\title{
GASEOUS OZONE FOR CONTROLLING POSTHARVEST FUNGAL DECAY OF TOMATO UNDER MARINE SHIPPING CONDITIONS. \\ El-Sheshtawi, M. ${ }^{1}$; S. Elafifi ${ }^{1}$; M. Elmazaty ${ }^{1}$; J. Bartz ${ }^{2}$ and $M$. Elkahky ${ }^{1}$ \\ ${ }^{1}$ Plant Path. Dept., Fac. of Agric., Mansoura Univ., Egypt. \\ ${ }^{2}$ Plant Path. Dept., Inst. of Food and Agric. Sci. (IFAS), University of \\ Florida, USA.
}

\begin{abstract}
Postharvest fungal decays of tomato caused by Alternaria alternata, Botrytis cinerea, Geotrichum candidum and Rhizopus stolonifer, result in significant economic losses during different stages from harvesting from farm to fork. The efficacy of ozone gas for controlling fungal postharvest fungal decays of tomato was evaluated. In the laboratory tests, Ozone $0.1 \mathrm{ppm}$ in the atmosphere above inoculated PDA didn't affect radial growth, fresh weight or dry weight of the previously mentioned fungi, but, the development of aerial mycelium over the cultures appeared to be blocked. On the other hand, ozone significantly decreased the spore germination of the most tested fungi. Ozone also, decreased the density of fungal spores in the air of a storage room when it was applied for 24 hours. In fruit tests, ozone $0.15 \mathrm{ppm}$ at $10^{\circ} \mathrm{C}$ and $\mathrm{RH} 99 \%$ prevented the development of lesions on wound-inoculated tomato fruits for 7 days. After 10 days, progressive lesions were observed but were smaller than those on control fruit. In contrast, when the treatment was applied at $22^{\circ} \mathrm{C}$, lesions developed similarly to those on control fruit but sporulation was inhibited. There was no evidence of phytotoxicity associated with these ozone treatments.
\end{abstract}

Keywords: Ozone- Postharvest decay-Tomato-Alternaria alternata-Botrytis cinerea, Geotrichum candidum, Rhizopus stolonifer.

\section{INTRODUCTION}

Tomato (Lycopersicon esculentum Mill.) is an important commercial crop in the world. Tomatoes are grown for fresh consumption or sometimes for food processing. Due to the variation in the environmental requirements of different tomato varieties, it could be produced around the year. Tomato fruits ripen on waves or flushes so, it is harvested manually one to three times a week according to weather conditions. The proper ripening stage for harvesting usually determined according to marketing plan, if it is for exportation purpose, fruits picked at mature green breaker or turner stages, on the other hand, if the fruits for local marketing, it is picked at pink or light red stages of color development. The harvested fruits are picked up into plastic or wooden baskets in the field. After that, the fruits are transported to packing houses where, they are prepared for marketing by washing, sanitizing, grading in color and size, and packing in cardboard boxes. Subsequently, the fruit cartons are transferred to temperature controlled storage rooms, $\left(7-15^{\circ} \mathrm{C}\right)$ where it could be stored up to two weeks prior shipping to markets.

In Egypt, Tomatoes are considered the most economic vegetable crop according to Food and Agriculture Organization (FAO) of the United Nation. 
Egypt is the $5^{\text {th }}$ country in the world in tomatoes production with about $8,639,024$ tons per year (FAOSTAT, official data, 2007).As a result, it could be very promising fresh crop for exportation also especially for European Union countries, and could play important eat in food conserve industry.

Various postharvest fungal pathogens attacke tomato fruits causing postharvest decay e. g. Alternaria alternata (black mould or Alternaria rot), Botrytis cinerea (grey mould), Geotrichum candidum (sour rot) and Rhizopus stolonifer (soft rot or Rhizopus rot) (Akhtar, et al. 1994). Postharvest decays dramatically affect the production and marketing of tomato fruits especially in the developing countries, where there are no enough facilities or precautions means to avoid such diseases. Blond, 1984 estimated postharvest losses of tomato fruits in Egypt, in different marketing system levels, by $43 \%$ of the total production.

Marine shipment of fresh fruits and vegetables offers a relatively inexpensive way for the intercontinental transport of fresh produce from production areas to markets. However, the time requirements and the marine environment often combine to decrease the profitability of the enterprise. For example, high humidity is required in the load to prevent shriveling of fruits, but in the same time, high humidity surrounding fresh produce over a long period of time, leads to the development of molds on the surfaces of many commodities. Some of these molds cause decay, whereas others are merely cosmetic. The presence of either one in a load arriving at a receiving point is a likely cause of rejection. Many measures have been used to maintain product quality and to prevent product decay. Cooling or cold storage together with controlled atmospheres are regularly used. Fumigation or heat treatment may be used prior to loading ships if insect quarantines are in effect. Direct fungicide applications are no longer accepted by most markets due to consumer concerns (Sapers, 1998; Smilanick 2003). Modifying the internal container atmosphere by intermittent or continuous application of low levels of gaseous oxidizers has been used to control mold and biofilm development on heat exchanger coils.

Since declaration of ozone as general recognize as safe (GRAS) from a panel of experts from food science in 1997 followed by the full approval of using ozone as a direct contact food sanitizer agent in 2003 in USA, the ozone technology and related fields started to attract more consideration. Ozone, as one of reactive oxygen spices (ROS) is one of the most powerful oxidizing agents, (Lide, 1991; Suslow, 1998). Neff, 1998 stated that, comparing with other disinfectants, the ozone gas has antimicrobial activity against a broad spectrum of microorganisms. Moreover, as a result of the quick decay of ozone gas in air and water, no residues were detected in any of treated fruits (Horvath et al.1985; Graham et al., 1997; Rice 1999).

Investigations on disinfection of foods, including the use of gaseous ozone to increase shelf-life and the use of ozone dissolved in water to sanitize surfaces of vegetables and fruit support the disinfection power of ozone (Graham et al., 1997; Kowalski et al., 1998; Kim et al., 1999; Kim and Yousef, 2000). 
Herein, we report an evaluation for continuous application of a low level of ozone for controlling postharvest decay of tomato fruits under a simulation of marine shipping conditions

\section{MATERIALS AND METHODS}

\section{Ozone Setup.}

All tests have been done in controlled environment chambers (Intellus controller, Percival ${ }^{\circledR}$ Scientific, INC, USA) to simulate the marine containers conditions. Ozone was generated with an EMS unit (AirOcare ${ }^{\circledR}$ generator Model ST-24, provided by Ingersoll Rand Company), this generator used the corona discharge technology and the level of generated ozone was regulated by controlling the output of the generator. Aeroqual ${ }^{\circledR}$ Handheld Monitor series 500 was used to monitor the ozone level in the chamber. Another chamber with the same temperature and humidity but without ozone was used for control treatments.

\section{Postharvest fungi and preparation of inoculum.}

Alternaria alternata, Geotrichum candidum, and Rhizoups stolonifer were isolated from naturally infested fruits tomato, while, Botrytis cinerea isolated from naturally infested strawberries' fruits. After isolation and purification of these fungi, the isolates were maintained on Potato Dextrose Agar Medium (PDA) and kept at $4{ }^{\circ} \mathrm{C}$ for further tests. Spores suspensions used in all tests were prepared by cultured the tested fungi on PDA plates for 3-7 days then, spores were harvested by adding 5-10 $\mathrm{ml}$ sterilized distilled water and $1 \mathrm{ml}$ of tween-20 to the developed cultures and scraping using plastic spatula. The resulted suspension was filtered through double layers of cheese cloth. concentration of the harvested spores' was determined either by using spectrophotometer with standard curves or Hemacytometer slide. The final concentration of the spore suspension was adjusted to be $1 \times 10^{6}$ spores $/ \mathrm{ml}$.

\section{Effect of gaseous ozone with different exposure times on the mycelial growth of tomato postharvest fungi.}

PDA plates were inoculated with five $10 \mu \mathrm{l}$ spots of $1 \times 10^{6} \mathrm{spore} / \mathrm{ml}$ of each tested fungus. After inoculation directly, the ozone treated plates were moved to the environmental controlled chamber supplemented with ozone generator. Control plates were moved to another chamber under similar conditions but without using ozone generator. The lids of all plates were removed then the chambers were tightly closed. Output of the generator was adjusted to give the final concentration of Ozone inside the chamber $0.1 \mathrm{ppm}$. Four exposure times were tested, 0 (serve as control), 24, 48, and 72 hours. After exposure time the treated plates were removed to control chamber. Four replicates were used. The temperature inside the chamber was adjusted to be $25 \pm 2{ }^{\circ} \mathrm{C}$ and the relative humidity was about $90 \%$.Colony diameter averages were measured after 72 hours from inoculation time for all plates, then the percentage of inhibition was calculated by comparing the colony diameters of treated plates with the colony diameter of the control plates. 


\section{Effect of gaseous ozone on fresh weight and dry weight of some postharvest fungi.}

Petri dishes of $90 \mathrm{~mm}$ in diameter received $20 \mathrm{ml}$ of Potato Dextrose Broth (PDB) and inoculated individually, with $100 \mu$ l of spores suspensions, 1 $\times 10^{6} \mathrm{spore} / \mathrm{ml}$ of each tested fungi mentioned before. Four replicates were used for each fungus. After inoculation the treated plates were moved to the Ozone chamber, and the lids of these plates were removed while, the control plates kept in another chamber under the same conditions but without ozone treatment. The generator's output was adjusted to give the final concentration of Ozone inside the chamber of $0.1 \mathrm{ppm}$. The temperature and the relative humidity were monitored using WatchDog ${ }^{\circledR}$ data logger and the average of the temperature was $25 \pm 2{ }^{\circ} \mathrm{C}$ and the relative humidity was about $98 \%$. After one week of incubation all plates treated and control cultures were filtrated through a funnel by using pre-dried, pre-weighed $9-\mathrm{cm}$ Whatman ${ }^{\circledR}$ no. 1 filter paper then left to air drying for 6 hours, then the mycelial mat of each culture weighed to get the fresh weights of mycelial, after that moved to drying oven at $70{ }^{\circ} \mathrm{C}$ for 24 hour and then reweighed to get the mycelial dry weight.

Effect of gaseous ozone on spore germination of some postharvest fungi in vitro.

$10 \mu \mathrm{l}$ of spore suspension, $1 \times 10^{6} \mathrm{spore} / \mathrm{ml}$ of each tested fungi were placed on glass cover slips and left to be air dried. Three slips were transferred to single Petri dish and this Petri dish was placed uncovered in ozone unit. While, another three slips were maintain in another Petri dish out of the unit to serve as control. The output of ozone generator was set up to give average of $0.5 \mathrm{ppm}$ ozone. After 48 hours, the cover slips from ozone treatment and from the control treatment were inverted to a single Petri dish contains Potato Dextrose Agar medium (PDA) and incubate at $20^{\circ} \mathrm{C}$ for 24 hour. After that, the spores were fixed with $2 \mathrm{ml}$ of $70 \%$ ethyl alcohol for 3 minutes. The germination incidence percentage (\%), as indicator for spore viability was determined by counting the number of germinating spores out of 200 randomly selected spores. Spores were counted as germinated only if the germ tube length was greater than the spore diameter.

Impact of gaseous ozone on the spore viability of postharvest fungi in the atmosphere of storage rooms.

To study the effect of ozone on spore viability in the atmosphere of storage rooms, 7 days old culture of Penicillium digitatum has been used to infest the air of one of the cold storage rooms $\left(5^{\circ} \mathrm{C}\right)$ by removing the lid of the culture and leave it opened under the storage room's fan for 4 hours. After that, spores sampling from two locations in the infested room has been done using air sampler, (MicroBio ${ }^{\circledR}$, Model MB1, Scientific Air Solutions, INC) with flow volume $25 \mathrm{~L}$. Three types of media have been used for spores trapping, Acidic Potato Dextrose Agar (APDA); Potato Carrot Agar (PCA); and Rosebengal Agar Based. Each type of this media was poured in Petri dishes size $100 \times 15 \mathrm{~mm}$ to fit the air sampler. Three plates of each type of media have been used in each location to serve as replicates. After spores trapping, all plates were incubated at $25^{\circ} \mathrm{C}$ for 48 hours before counting the number of colonies in each plate. After the first spore trapping, ozone unit was turned on in the storage room, and the output of the unit was adjusted to 
give $0.1 \mathrm{ppm}$ for 24 hours. A second spores trapping has been done in the same locations using the same air sampler with the same flow volume and the same types of media. After that, the plates were also, incubated at $25^{\circ} \mathrm{C}$ for 48 hours before counting the number of colonies in each plate.

Effect of gaseous ozone on decay incidence of tomato fruits under different temperatures.

Light red tomato fruits were surface sterilized by soaking in $5 \%$ Clorox $\circledast$ solution for two minuets then rinsed with distilled water. Each fruit surface was wounded in five wounds, $2 \mathrm{~mm}$ in depth and $2 \mathrm{~mm}$ in diameter. Each wound was inoculated with $10 \mu \mathrm{l}$ of spore suspension $\left(10^{6} \mathrm{spore} / \mathrm{ml}\right)$ of each fungus. After inoculation directly, half of the inoculated fruits were moved to environmentally controlled chamber containing EMS unit .The output of the EMS unit was adjusted to give $0.15 \mathrm{ppm}$ as a final concentration inside the chamber. Aeroqual ${ }^{\circledR}$ Handheld Monitor series 500 was used to check the ozone level inside the chamber. The other halves of inoculated fruits, which serve as control fruits, were moved to another chamber having the same conditions but without ozone. The temperature and the relative humidity inside both chambers were set to $22 \pm 2{ }^{\circ} \mathrm{C}$ and $99 \%$. Same test was done but temperature of chambers was set to $10 \pm 2{ }^{\circ} \mathrm{C}$ to simulate the same condition of marine container. Lesions diameters were measured after 7, 10, 15 days.

Statistical Analysis.

Tukey test for multiple comparisons among means was utilized (SAS Institute Inc., Cary, NC).

\section{RESULTS AND DISCUSSION}

Effect of gaseous ozone with different exposure times on the mycelial growth of tomato postharvest fungi.

Insignificant inhibition was noticed in the diameter of mycelial growth of all tested fungi ranged from $3 \%$ in case of $\mathrm{R}$. stolonifer when it exposed to $0.1 \mathrm{ppm}$ ozone for 24 and 48 hours to $5.36 \%$ in case of the same fungus when it exposed to the same level for 72 hours. The colony diameters of all tested fungi at different levels of exposure time were not significantly different when compared to untreated control (Fig. 1). However, the aerial mycelial height was clearly inhibited after exposure of $0.1 \mathrm{ppm}$ ozone for 24 hours at $25 \stackrel{\circ}{\circ}$ (Data not shown). Moreover, it was obvious that the ozone treatment affected the spore production in all tested fungi because no spores were noticed in the treated plates in particular in case of $B$. cinerea and $R$. stolonifer. When all treated plates transferred to fresh air, all fungi recovered the aerial mycelial growth and sporulation ability. Similar results were obtained by Sharpe et al. 2009 when they tested the effect of 450 and 600 $\mathrm{ppm}$ of ozone on the mycelial growth of $B$. cinerea and S. sclerotiorum for 48 hours. They also, noticed the severely reduction in aerial mycelial growth caused by ozone treatment. It appears that, the constant exposure to an ozone enriched atmosphere for a longer period was more effective at inhibiting mycelial growth of the tested fungi. 


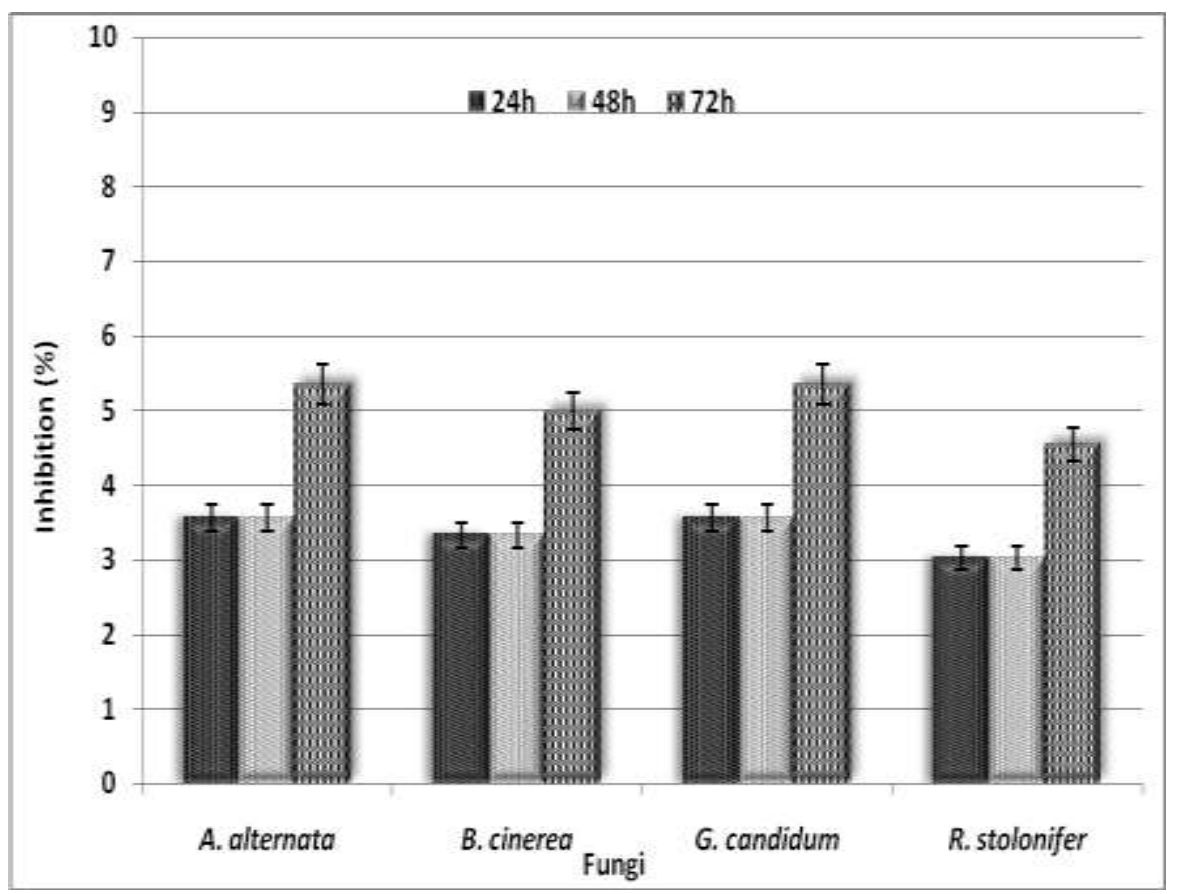

Fig. (1): Effect of various exposure times of $0.1 \mathrm{ppm}$ ozone on the radial growth of some postharvest decay fungi

\section{Effect of gaseous ozone on the fresh weight and dry weight of some} postharvest fungi.

Results obtained from current study showed that both of fresh and dry weights of biomass of $A$. alternata and $B$. cinerea were insignificantly inhibited by $15.87,14.33,16.77$ and $13.40 \%$ respectively when the liquid cultures of these fungi exposed to $0.1 \mathrm{ppm}$ ozone for one week. On the other hand, a slight inhibition was noticed in case of $G$. candidum and $R$. stolonifer under the same conditions. It was remarkable that all fungal growths were grown in subsurface of the liquid media; this could be due to the effect of ozone on aerial growth and because of poor solubility of ozone in liquids.

Effect of gaseous ozone on spore germination of some postharvest fungi in vitro

Exposing fungal spores on a glass slide covers to $0.5 \mathrm{ppm}$ ozone resulted in significant inhibition for spore germination of most tested spores except in case of $A$. alternata, the reduction of spore germination percentage was insignificant when it is compared to untreated control which exposed to fresh air (Fig 3). 


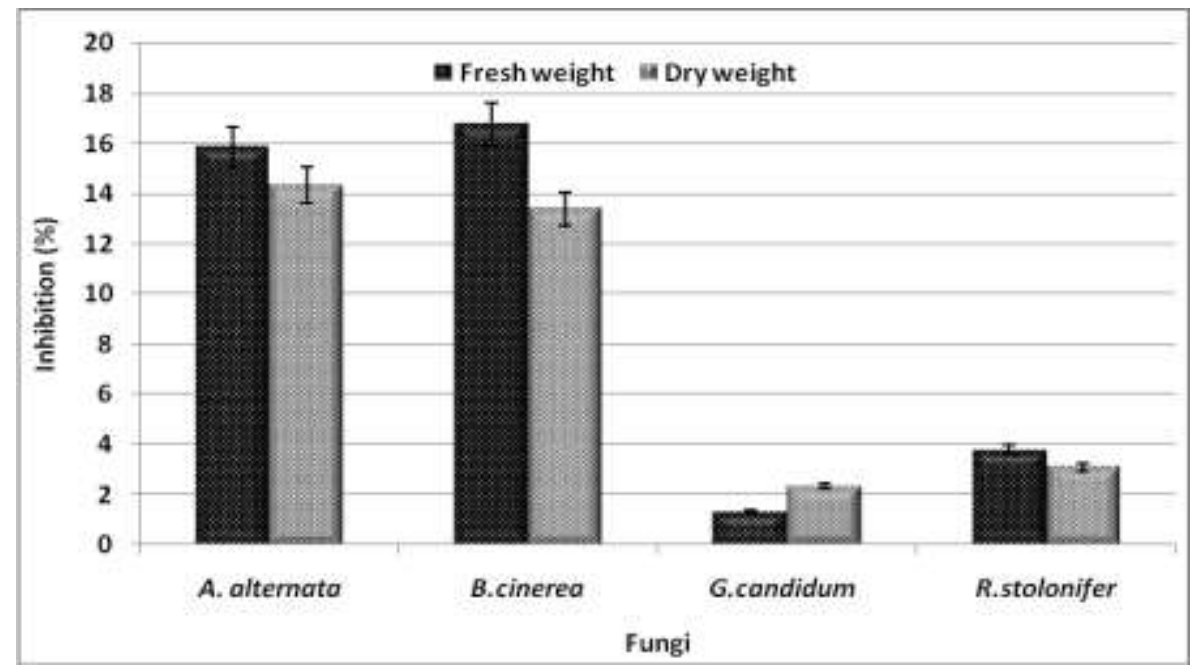

Fig. (2 ): Effect of $0.1 \mathrm{ppm}$ ozone on the fresh and dry weight of some postharvest decay fungi

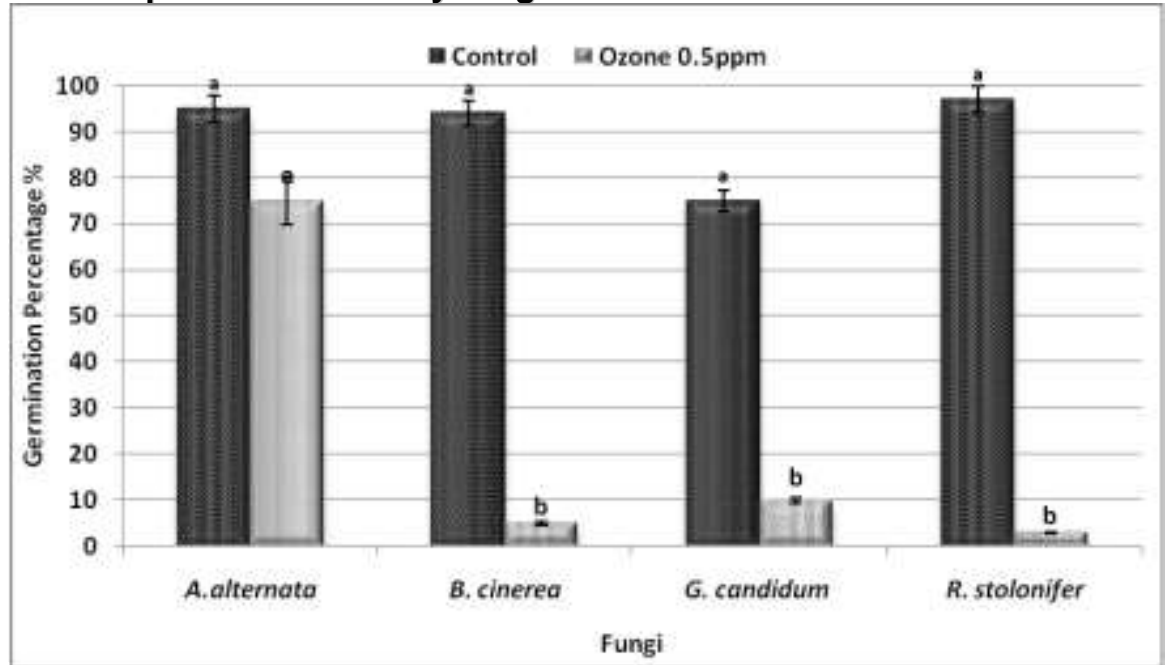

Fig. (3): Effect of $0.5 \mathrm{ppm}$ ozone on the spore germination of some postharvest decay fungi in vitro.

Impact of gaseous ozone on the spore viability of postharvest fungi in the atmosphere of storage rooms.

Treating storage room with $0.1 \mathrm{ppm}$ of ozone resulted on significant reduction of fungal spore populations in the room air Between all used media Acidified Potato Dextrose Agar seemed to be the most available medium for detecting fungal spores in the room atmosphere. The reduction in fungal spores population numbers will be translated to reduction in the suspected new infection during storage or shipping. Moreover, this will decrease the postharvest decay of the stored or transported shipments (Fig. 4). 
El-Sheshtawi, M. et al.

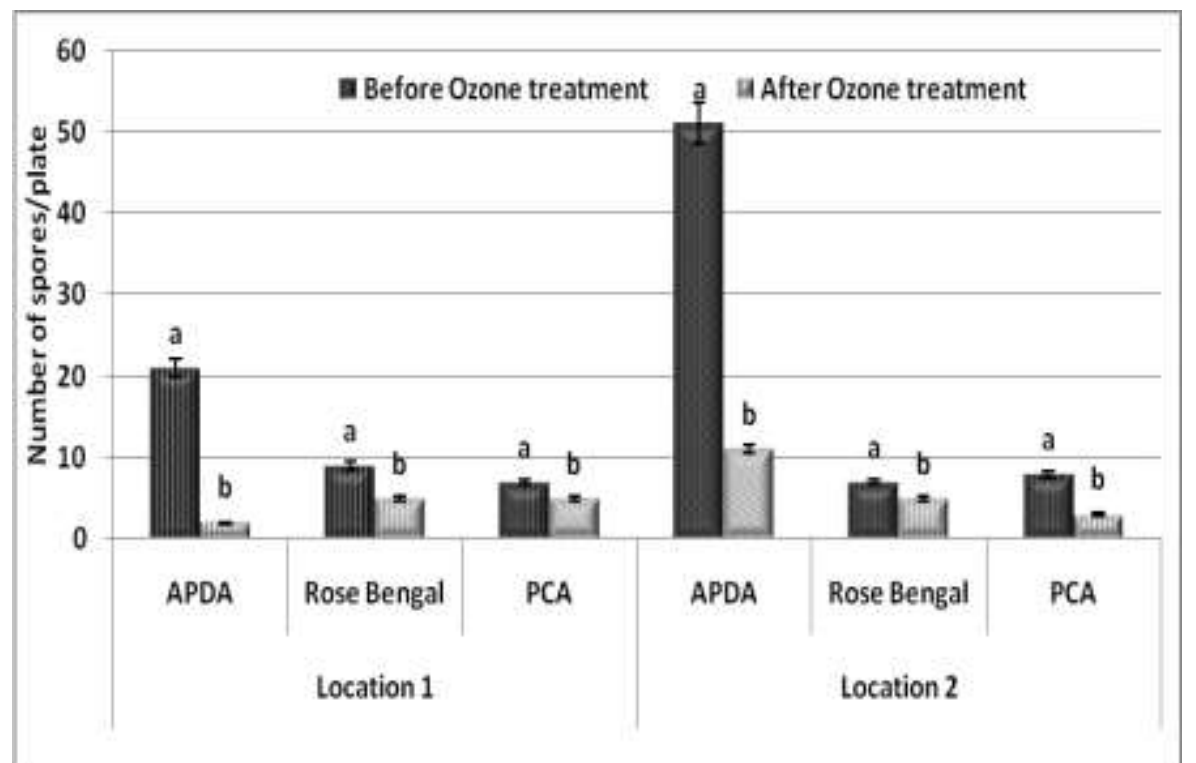

Fig. (4): Impact of $0.1 \mathrm{ppm}$ ozone on the spore viability of postharvest decay fungi in cold storage rooms using different types of media.

\section{Effect of gaseous ozone on decay incidence of tomato fruits under different temperatures.}

Data in Fig. $5 \& 6$ showed that at $22^{\circ} \mathrm{C}$, no significant differences were observed between averages of lesion diameters of infested fruits treated with $0.15 \mathrm{ppm}$. Ozone and untreated infested fruits, either after 7 days or after 10 days. The lesions diameter averages in the treated fruits were always less than the lesion diameter averages of the untreated fruits. On the other hand, it was noticed that when the same treatments applied at $10^{\circ} \mathrm{C}$, there were noticeable, significant differences between the treated fruits with $0.15 \mathrm{ppm}$ ozone and untreated fruits. The combination of $0.15 \mathrm{ppm}$ ozone and the cold storage at $10{ }^{\circ} \mathrm{C}$ prevent the fungal growth in case of A. alternata, B.cinerea, and G. candidum for 7 days. While after 10 days, the decay lesions start to develop in all treated fruits but the diameters of these fungal lesions were smaller than those in the untreated fruits. Moreover, in all treated fruits with ozone at temperatures, no aerial mycelia or any type of sporulation were noticed on the inoculated fruits. At both temperatures no sign of phytotoxicity was observed on the treated fruits with 0.15 ppmone. 


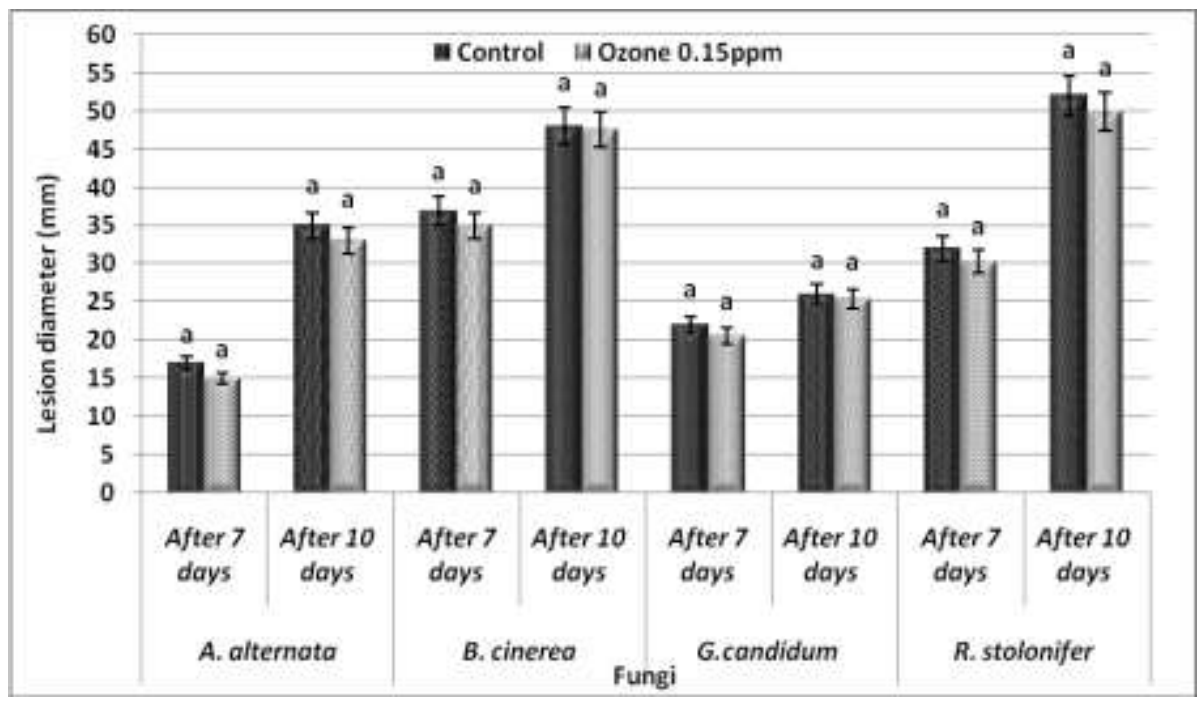

Fig. (5): Effect of $0.15 \mathrm{ppm}$ ozone on tomato decay caused by different fungi at $22{ }^{\circ} \mathrm{C}$ and $99 \% \mathrm{RH}$ after $7 \& 10$ days.

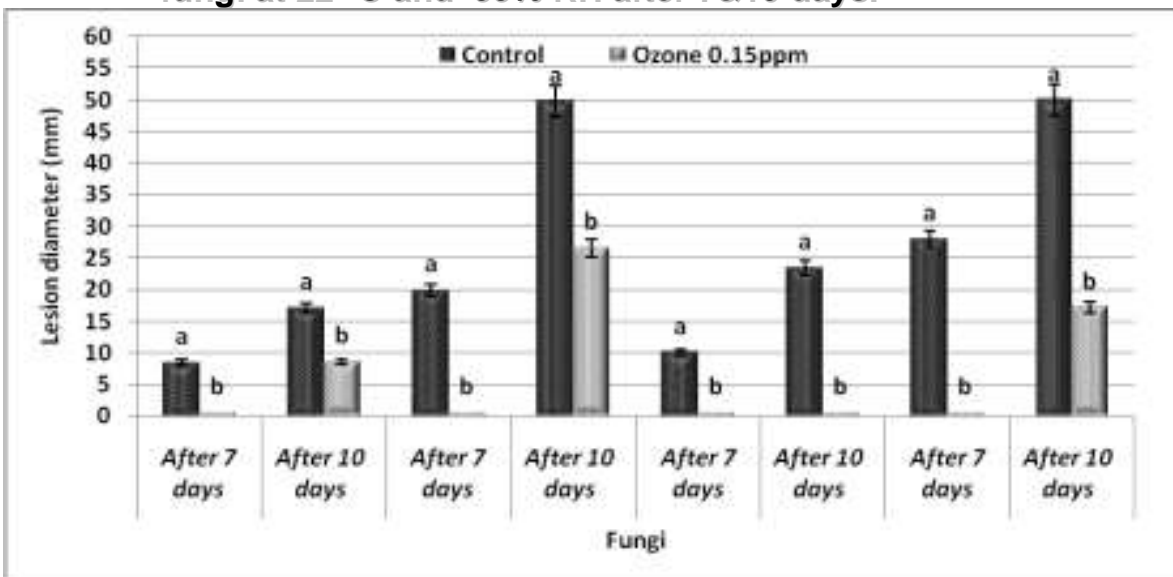

Fig. (6): Effect of $0.15 \mathrm{ppm}$ ozone on tomato decay caused by different fungi at $10{ }^{\circ} \mathrm{C}$ and $99 \% \mathrm{RH}$ after $7 \& 10$ days

\section{DISCUSSION}

Fungal development on agar measured by colony diameter was un affected by ozone exposure at any of tested exposure times, even when colony morphology appeared to be affected, this was reflected on inhibition of aerial mycelium growth and spores production in all tested fungi. These results came in agreement with previous work done by Tzortzakis, et al. 2007, and Hildebrand, et al. 2008. Moreover, in the present study slight effect of ozone was observed on the fungal biomass cultured in liquid media. same results was obtained by Tzortzakis, et al. 2007 and Tzortzakis, et al. 2008 where they found that there was no significant effect of ozone $(0.2 \mathrm{ppm})$ on 
the fungal biomass of $A$. alternata, B. cinerea and Colletotrichum coccodes cultured an aqueous media. They referred that it may belong to the relatively poor solubility of ozone in aqueous media at room temperature. Fungi cultured in liquid media would have been subjected to lower concentrations than fungi exposed to atmospheric ozone enrichment.

In the current study, continuous application of low ozone level reduced spoilage caused by commercially important Postharvest pathogens. This was reflected on extending the shelf life of tomato fruits. The ozone treatment combined with cold storage at $10^{\circ} \mathrm{C}$ delayed the disease incidence in most tested fungi for 7 days. Moreover, the same treatment significantly delayed the disease development which was appeared on reducing the lesion diameter in all tested fungi. It is possible that the ozone restricted or killed a percentage of active spores at the inoculum or interfered in the fungal colonization process. On the other hand, Ozone couldn't totally prevent the disease incidence. The incapability of gaseous ozone to penetrate the infected tissue and control the infection has been reported formerly in numerous studies (Spotts and Cervantes, 1992; Smilanick et al., 1999; Hildebrand et al., 2001; Palou et al., 2001, 2002; Nicoue' et al., 2004). The reduction of the rate of lesion size could be due to the ability of ozone to induce formation of some chemical compounds which contribute in increasing tolerance and resistance of the treated fruits against fungal infection. These chemicals could affect the speed of colonization process, or directly affect the pathogen growth. Song et al., 2003 found that the treated carrot roots with $1000 \mathrm{nl} / \mathrm{L}$ ozone caused accumulation of 6- methoxymellein which is known to inhibit B. cinerea (Mercier et al., 1993). Tzortzakis, et al. 2008 suggested that the delay of the pathogen development in the inoculated fruits could be related with the reaction between ozone and ethylene. It is known that ozone reacts rapidly to remove ethylene (Rice et al., 1982; Rice, 2002); this reaction might slow mycelial development by preventing cell wall disassembly and maintaining the firmness of the fruit.

In vitro tests declared that ozone treatment significantly suppressed the spores germination of the tested fungi. This result is consistent with numerous reports that found that ozone treatment reduced spore viability in several plant pathogens (Krause and Weidensaul, 1977; Khan and Khan, 1999; Tzortzakis et al., 2007a, b). The Ozone mechanism in suppressing the germination of the fungal spores is not clear. However, it was obvious that ozone effect on the spores is affected by some important factors, i. e., spore morphology, moisture content, thickness of the spore wall, number of cells, and spore pigment. Dry, multi celled and thick-walled spores with pigment often exhibiting greater resistance to ozone than hydrated, single celled, thin walled, and hyaline spores. This was clearly showed in case of $A$. alternata, where the spores were more resistant to the ozone effect.

In the present study the ozone treatment obviously reduced the sporulation of all tested fungi, these results came in agreement with previous work done by Hildebrand et al., 2001; Palou et al., 2002. In contrast, in some cases ozone treatment stimulated spore production, Hildebrand, et al. 2008, stated that treating carrot roots with $50 \mathrm{~nL} / \mathrm{L}$ ozone gas stimulated spore production by $B$. cinerea in lesions. The inhibition of pathogens sporulation by 
ozone is extremely valuable, because this will be reflected on the amount of inoculum available for the reinfection of produce during marine shipping (Song et al., 2000; Palou et al., 2002), and this will lead to break the infection cycle of the pathogens (Smilanick, 2003).

For the fruit quality, no phytotoxicity signs were observed or any effect on fruit quality of the treated fruits, this came in harmony with previous work done by Tzortzakis, et al., 2007, where they found that the ozone treatment did not affect any of quality characteristics including, weight loss, antioxidant status, $\mathrm{CO}_{2} / \mathrm{H}_{2} \mathrm{O}$ exchange, ethylene production or organic acid, vitamin $\mathrm{C}$ (pulp and seed) and total phenolic content of treated fruits with 0.005-0.15 ppm ozone.

The present study suggests the potential use of continuous low level ozone for protecting of fresh produce in during marine shipping. Postharvest fungal decay development was suppressed in infected fruit exposed to low level ozone combined with cold storage $\left(10^{\circ} \mathrm{C}\right)$. The benefits associated with ozone treatment also, including prevention of any new infection during shipping by controlling the fungal sporulation and inactivating any spores inside the containers atmosphere. There would seem to be real commercial potential for using ozone in marine container. Much care also needs to be taken to monitor and control the level of ozone gas inside the containers during the shipping since the uncontrolled generation of the gas inside the shipping containers could represent a significant health concern from a worker-exposure perspective.

\section{REFERENCES}

Akhtar, K. P.; Matin, M.; Mirza, J. H., Shakir, A. S., and Rafique M. 1994.Some studies on the postharvest diseases of tomato fruits and their chemical control. Pakistanian Journal of Phytopathology, 6: 125-129.

Blond, R.D. 1984. The agricultural development systems project in Egypt. Univ. Calif., Davis. Pp. 190-194.

Graham D. M.; Pariza, M. ; Glaze, W.H.; Newell, G.W.; Edman J.W., and Borzelleca, J.F., 1997. Use of ozone for food processing. Food Technology, 51, 72-75.

Hildebrand, P. D.; Forney, C. F.; Song, J.; Fan, L.; McRae, K. B. . 2008. Effect of a continuous low ozone exposure $(50 \mathrm{~nL} L-1)$ on decay and quality of stored carrots. Postharvest Biology and Technology 49,397402.

Hildebrand, P.D., Song, J., Forney, C.F., Renderos, W.E., Ryan, D.A.J., 2001. Effects of corona discharge on decay of fruits and vegetables. Acta Hort. 553, 425-426.

Horvath, M.; Bilitzky, L.; and Huttner, J. 1985. Fields of utilization of ozone. in Ozone, Clark R J H (ed.), Elsevier Science, New York, 257-316.

Khan, M.R., Khan, M.W., 1999. Effects of intermittent ozone exposures on powdery mildew of cucumber. Env. Exp. Bot. 42, 163-171.

Kim J. G., Yousef A. E., and Chism G. W., 1999. Use of ozone to inactivate microorganisms on lettuce. Journal of Food Safety, 19, 17-34. 
Kim, J. G., and Yousef, A. E., 2000. Inactivation kinetics of foodborne spoilage and pathogenic bacteria by ozone. Journal of Food Science, $65,521-8$.

Kowalski, W. J.; Bahnfleth, W. P. and Whittam, T. S., 1998. Bactericidal effects of high airborne ozone concentrations. Ozone Science Engineering, 20, 205-21.

Krause, C.R.,Weidensaul,T.C., 1977. Effects of ozone on the sporulation, germination and pathogenicity of Botrytis cinerea. Phytopathology 68, 195-198.

Lide, D.R., 1991. CRC Handbook of Chemistry and Physics, second ed. CRC Press, Boca Raton, FL (Section 16, p. 16).

Mercier, J., Arul, J., Ponnampalam, R., Boulet, M., 1993. Induction of 6methoxymellein and resistance to storage pathogens in carrot slices by UV-C. J. Phytopathol. 137, 44-54.

Neff, J., 1998. New disinfectant from out of the blue. Food Process, 5, 135137.

Nicoue' , E.E., E'mond, J.P., Vuillemard, J.C., Nascimento-Nunes, M.C.-do., 2004. Destruction de Rhizopus stolonifer et de Botrytis cinerea par des traitements ozone/ions. Phytoprotection 85, 81-87.

Palou, L., Crisosto, C.H., Smilanick, J.L., Adaskaveg, J.E., Zoffoli, J.P., 2002. Effects of continuous $03 \mathrm{ppm}$ ozone exposure on decay development and physiological responses of peaches and table grapes in cold storage. Postharvest Biol. Technol. 24, 39-48.

Palou, L., Smilanick, J.L., Crisosto, C.H., Mansour, M., 2001. Effect of gaseous ozone exposure on the development of green and blue molds on cold stored citrus fruit. Plant Dis. 85, 632-638.

Rice, R.G., 1999. Ozone in the Unites States of America-states of the art. Ozone Science Engineering, 21, 99-118.

Rice, R.G., 2002. Century 21—pregnant with ozone. Ozone Sci. Eng. 24, 115.

Rice, R.G., Farquahar, J.W., Bollyky, J.L., 1982. Review of the applications of ozone to increasing storage times of perishable goods. Ozone Sci. Eng. 4, 147-163.

Sapers, G. M., 1998. New technologies for safer produce-chemical based treatments and decontamination by washing. Proceeding Conference on fresh Fruit and Vegetables: Food Safety Challenges (Sponsored by National Center of Food Safety Technology, Chicago,USA, May 12-14.

Sharpe, D.; Fan, L.; Mcrae, K.; Alker, B.; Mackay, R.; and Doucette C. 2009. Effects of Ozone Treatment on Botrytis cinerea and Sclerotinia sclerotiorum in Relationto Horticultural Product Quality. Journal of Food Science, 74(6), M250-M257.

Smilanick, J. L., 2003. Postharvest Use of Ozone on Citrus Fruit. Packinghouse Newsletter 199, USA, pp. 1-6.

Smilanick, J.L., Crisosto, C.H., Mlikota, F., 1999. Postharvest use of ozone on fresh fruit. Perishables Handl. Q 99, 10-14.

Song, J., Fan, L., Hildebrand, P.D., Forney, C.F., 2000. Biological effects of corona discharge on onions in a commercial storage facility. HortTechnology 10, 608-612. 
Song, J., Fan, L., Forney, C.F., Hildebrand, P.D., Jordan, M.A., Renderos,W.,McRae, K.B., 2003. Ozone and 1-MCP treatments affect the quality and storage life of fresh carrot. Acta Hort. 628, 295-301.

Spotts, R.A., Cervantes, L.A., 1992. Effect of ozonated water on postharvest pathogens of pear in laboratory and packinghouse tests. Plant Dis. 76, 256-259.

Suslow, T., 1998. Basics of ozone application for postharvest treatment of fruits and Vegetables. Perishables Handling Quarterly, 94, 9-11.

Tzortzakis, N.; Singleton, I. and Barnes, J. 2008. Impact of low-level atmospheric ozone-enrichment on black spot and anthracnose rot of tomato fruit. Postharvest Biology and Technology 47: 1-9.

Tzortzakis, N.G., Borland, A., Singleton, I., Barnes, J.D., 2007b. Impact of atmospheric ozone-enrichment on quality-related attributes of tomato fruit. Postharvest Biol. Technol. 45, 317-325.

Tzortzakis, N.G., Singleton, I., Barnes, J.D., 2007a. Deployment of lowlevelozone-enrichment for the preservation of chilled fresh produce. Postharvest Biol. Technol. 43, 261-270.

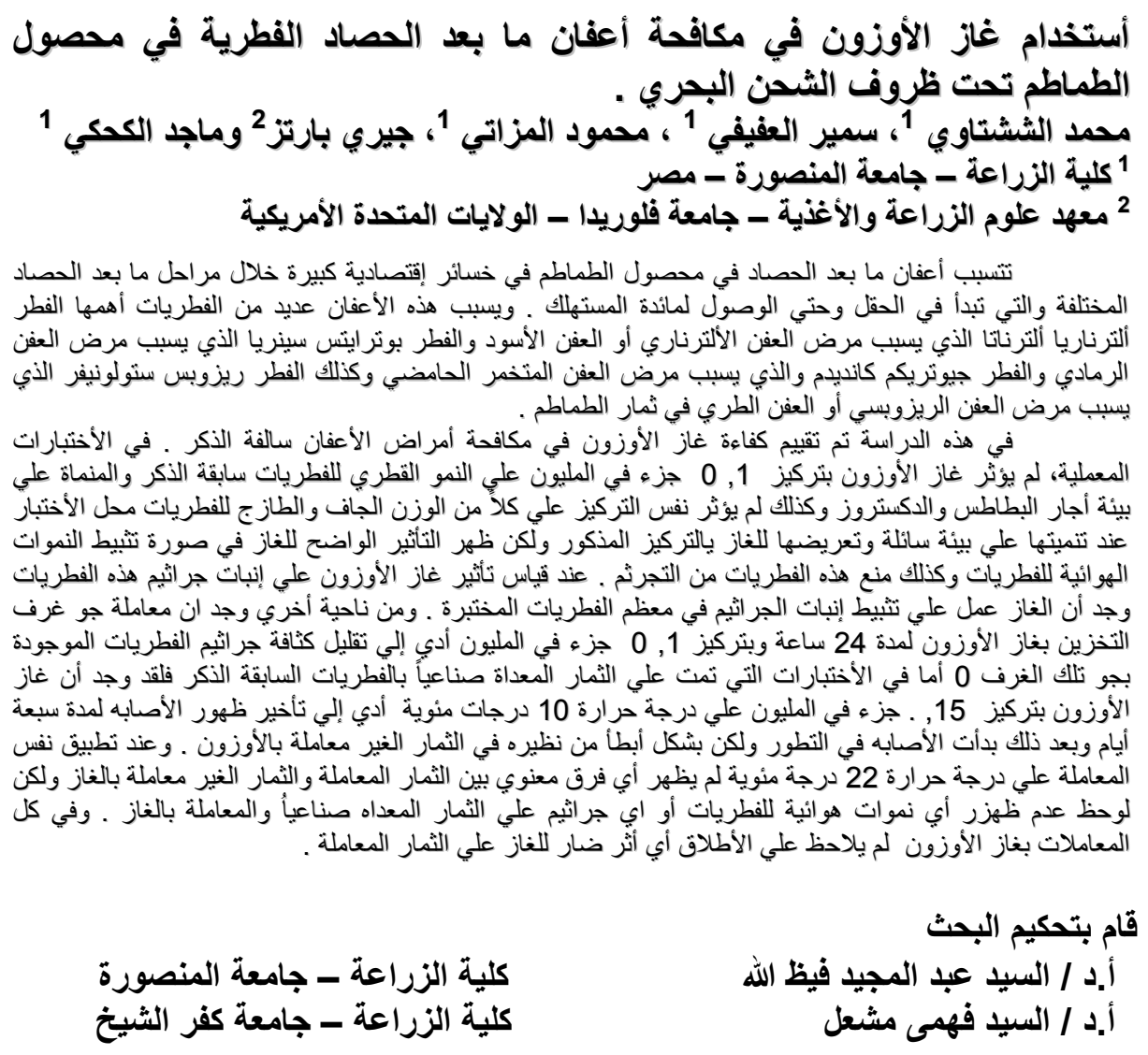

